\title{
Risks of acute traumatic intracranial haematoma in children and adults: implications for managing head injuries
}

\author{
Graham M Teasdale, Gordon Murray, Elaine Anderson, A David Mendelow, Robert MacMillan, \\ Bryan Jennett, Marie Brookes
}

\begin{abstract}
Objective-To determine the factors influencing the risk of an acute traumatic intracranial haematoma in children and adults with a recent head injury.

Design-Prospective study of incidence of risk factors in samples of patients attending accident and emergency departments and in all patients having an acute traumatic intracranial haematoma evacuated in one regional neurosurgical unit during 11 years.

Setting-Accident and emergency departments in Scotland or Teesside and regional neurosurgical centre in Glasgow.

Patients -8406 Adults and children ( $\leqslant 14$ years) who attended accident and emergency departments and 1007 consecutive patients who had an operation for an acute traumatic intracranial haematoma. Data were complete in 8366 and 960 patients respectively.

Results-Overall, children were less at risk than adults (one in $2100 v$ one in 348 respectively). In both age groups the presence of a skull fracture and changes in conscious level permitted identification of subgroups of patients with widely differing degrees of risk. In children the absolute risk ranged from one in almost 13000 without a fracture or altered conscious level to one in 12 for a child in a coma and with a fracture; the pattern was similar in adults, the risks in corresponding groups ranging from one in almost
\end{abstract} 7900 to one in four.

Conclusions-Although children attending hospital after a head injury have a lower overall risk of a traumatic haematoma, the main indicators of risk, a skull fracture and conscious level, are the same as in adults, and the pattern of their combined effect is similar. Guidelines for managing adults with recent head injury may therefore be applied safely to children; with the increasing provision of facilities for computed tomography they should be revised to ensure early scanning of more patients with head injury.

\section{Introduction}

Prompt evacuation of an intracranial haematoma is crucial in improving the outcome of head injury. ${ }^{2} \mathrm{We}$ have previously shown that adults at high risk of a haematoma may be identified by the finding of a skull fracture and altered consciousness on examination in the accident and emergency department. ${ }^{3}$ Guidelines based on this finding ${ }^{+}$are now widely used in the United Kingdom, but they do not apply to children, who account for almost half the attenders at hospital after a recent head injury.

This study aimed at determining whether the factors that identify the risk of an intracranial haematoma in adults apply also to children and whether other data available at the time of the first attendance at hospital improve assessment of the degree of risk in either age group. In addition to information about a skull fracture, we analysed the effect on risk of a haematoma of the patient's sex; the cause of injury; the level of consciousness on arrival; and, in fully conscious adults, whether there was a history of altered consciousness or amnesia immediately after the injury. The results were used to update guidelines for managing head injury in all age groups.

\section{Patients and methods}

PATIENTS ATTENDING ACCIDENT AND EMERGENCY DEPARTMENTS

These 8406 patients comprised 3557 patients attending hospitals in Scotland during 1974, ${ }^{6} 768$ attending Glasgow Royal Infirmary, 710 studied in Teesside, ${ }^{8}$ and 3371 attending Monklands District General Hospital. ${ }^{9}$ The patients included 2773 adults described previously $^{3}$ and, respectively, 1515, 33, 345, and 1721 children, defined as $\leqslant 14$ years old. Data were not available for all features in all patients; tables I-III show the total numbers of patients on whom data were complete in the different subcategories. Data from all sources were pooled with adjustment for differences between the samples in the proportions of children and adults.

PATIENTS OPERATED ON FOR A TRAUMATIC INTRACRANIAL HAEMATOMA

The Glasgow Neurosurgical Unit serves a population of $2 \cdot 7$ million. We used data collected prospectively from 1974 and 1984 on 988 adults and 119 children who had had surgical evacuation of an acute traumatic intracranial haematoma. The data represent virtually all the acute traumatic intracranial haematomas operated on in our region. We excluded infants with fluid subdural collections that were evacuated by fontanelle tapping. There were six children aged $<2$ years; each had an acute extradural haematoma evacuated within a day after injury. No child had a craniotomy for an acute traumatic intracranial haematoma at the regional specialist paediatric hospital during the study.

\section{DEFINITIONS}

Children were defined as being $\leqslant 14$ years old. Only two types of injury were analysed: that resulting from a road traffic accident (to an occupant of a vehicle, a pedal or motor cyclist, or a pedestrian) or from another cause. Patients were considered to have a skull fracture on the basis of the $x$ ray report of the staff of the accident and emergency department or if the patient had clinical signs of a fracture of the base of the skull, whether or not a skull $x$ ray was performed. Information in the records of the department was used to stratify patients into three groups according to their level of consciousness: orientated and alert, impaired consciousness, and coma. On the Glasgow coma scale ${ }^{10}$ the levels of consciousness in these groups corresponded to scores in adults of 15, 9-14, and 3-8 respectively. Adults who were fully orientated on arrival were further subdivided according to whether or not they had a history of a period of altered consciousness immediately after the injury, ranging from transient impairment of awareness and memory 
to loss of consciousness for several minutes or more with recovery before admission. Data on consciouness and amnesia in children were insufficient to support a similar analysis.

\section{CALCULATION OF RELATIVE AND ABSOLUTE RISKS}

Relative risk was defined as the chance that a patient who shows one or more of the features studied will develop a traumatic intracranial haematoma compared with a patient without these features. Relative risks are estimated directly from the numbers of patients observed in the sample populations; they are useful in identifying the importance of different features in comparing groups of patients. Absolute risks were defined as the frequency of development of a traumatic haematoma in the total number of patients with a particular set of features who attended accident and emergency departments. They are needed to take decisions on individual patients and to formulate policies for managing future cases.

The number of patients with head injury attending accident and emergency departments in the west of Scotland during 1974-84 was required as the denominator for calculations of absolute risk and was estimated as described previously ${ }^{3}$ on the basis of surveys performed in $1974^{6}$ and $1984,{ }^{5}$ giving figures of 344000 adults and 255000 children. In only 861 of the 988 adults and 99 of the 119 children in the haematoma sample were complete data available. Assuming that the patients with incomplete data were randomly distributed, the total numbers in the accident and emergency group were reduced by a corresponding factor, giving a corrected base of 299781 adults and 212143 children

Both the relative and absolute risks are presented with approximate 95\% confidence intervals." The confidence intervals shown for the absolute risks did not reflect the uncertainty associated with estimating the size of the total populations at risk and are thus slightly too narrow.

When relating risks to more than two factors simultaneously the number of patients with any given combination of features was usually too small to permit the direct approach described above. Instead separate log-linear models were fitted to multiway tables for the accident and emergency data and the haematoma data. ${ }^{12}$ The corresponding confidence intervals were also based on the results of the log-linear modelling.

\section{Results}

Tables I-III show data on the relative frequency of the various features in patients attending accident and emergency departments and those who had an operation for a traumatic intracranial haematoma and on the effects of various features on the relative and absolute risks of a haematoma.

Age-Overall, children were less at risk of a haematoma than adults (one in $2100 v$ one in 348 respectively), and analyses were therefore carried out separately for the two age groups.

Skull fracture was found in only a few children and adults attending accident and emergency departments (table I). By contrast, most patients who developed a haematoma had a skull fracture, although this was somewhat less common in children than adults $(62 \%$ v $77 \%$ respectively). The effect of a fracture on the relative risk was slightly less in children than adults, but the difference was not significant.

Conscious level-Separation of patients into those with impaired consciousness (in adults Glasgow coma score 9-14) and in coma (Glasgow coma score 3-8) gave additional information about risks in all but one group, that of adults with a skull fracture, who were at extremely high risk of a haematoma (one in four or five) irrespective of the degree of impairment of consciousness. With this exception, more severe impairment of consciousness increased the risks of a haematoma by similar degrees in children and adults (table I).

History of altered consciousness - The low risk of an intracranial haematoma in adults who were fully alert when they attended hospital who did not have a skull fracture was confirmed. Among alert adults, those who did not have a history of a preceding temporary alteration in consciousness were about four times less at risk of having a traumatic haematoma (table II), but even with such a history the risk remained low (one in $6663)$. The effect of a history of altered consciousness was significant $(\mathrm{p}<0 \cdot 01)$.

Sex of patient and cause of injury did not alter the estimates of relative risk derived from the presence of a skull fracture and the level of consciousness (table III).

Yearly incidence-We estimated the number of patients in each category per year and the number who developed a haematoma per million population. Most intracranial haematomas occurred in adults with head injury who on arrival have a skull fracture and persisting impairment of consciousness (table IV). In the remaining patients similar numbers of haematomas occurred in two groups of adults: those with a skull fracture who were fully conscious and those who did not have a fracture but who had either impaired consciousness or were in coma. Fewer children developed traumatic intracranial haematoma, because the overall risks were lower and because more children attended who were at very low risk.

TABLE I - Incidence of skull fracture and altered conscious level in relation to risk of intracranial haematoma in samples of children and adults with head injury

\begin{tabular}{|c|c|c|c|c|c|c|}
\hline & $\begin{array}{l}\text { Haematoma } \\
\text { group }\end{array}$ & $\begin{array}{l}\text { Accident and } \\
\text { emergency group }\end{array}$ & Relative risk (1:) & $\begin{array}{c}95 \% \text { Confidence } \\
\text { interval }\end{array}$ & Absolute risk (1:) & $\begin{array}{c}95 \% \text { Confidence } \\
\text { interval }\end{array}$ \\
\hline \multicolumn{7}{|l|}{ Without skull fracture: } \\
\hline Fully conscious & 35 & 4378 & 1 & & 7866 & 5700 to 10900 \\
\hline With impaired consciousness & 90 & 258 & 44 & 29 to 66 & 180 & 140 to 230 \\
\hline In coma & 72 & 31 & 291 & 170 to 500 & 27 & 18 to 41 \\
\hline \multicolumn{7}{|l|}{ With skull fracture: } \\
\hline Fully conscious & 86 & 61 & 176 & 110 to 280 & 45 & 32 to 61 \\
\hline With impaired consciousness & 248 & 20 & 1551 & 870 to 2800 & $5 \cdot 1$ & $3 \cdot 2$ to $8 \cdot 0$ \\
\hline In coma & 330 & 19 & 2173 & 1200 to 3900 & $3 \cdot 6$ & $2 \cdot 3$ to $5 \cdot 7$ \\
\hline \multirow[t]{2}{*}{ Total } & 861 & 4767 & & & & \\
\hline & \multicolumn{5}{|c|}{ Children } & \\
\hline $\begin{array}{l}\text { Without skull fracture: } \\
\text { Fully conscious }\end{array}$ & 16 & 3409 & 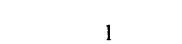 & & 12559 & 8000 to 19700 \\
\hline With impaired consciousness & 12 & 118 & 22. & 10 to 47 & 580 & 330 to 1000 \\
\hline In coma & 10 & 11 & 194 & 71 to 530 & 65 & 28 to 150 \\
\hline \multicolumn{7}{|l|}{ With skull fracture: } \\
\hline Fully conscious & 18 & 48 & 80 & 38 to 170 & 157 & 95 to 260 \\
\hline With impaired consciousness & 19 & 8 & 506 & 190 to 1300 & 25 & 11 to 55 \\
\hline In coma & 24 & 5 & 1023 & 340 to 3100 & 12 & $4 \cdot 8$ to 31 \\
\hline Total & 99 & 3599 & & & & \\
\hline
\end{tabular}


TABI.E. II - Absolute risk of traumatic intracranial haematoma approximate $95^{\circ}$ "confidence interials) in fully conscious adults attending accident and emergency departments

\begin{tabular}{lcc}
\hline & No altered consciousness & History of altered consciousness \\
\hline Without skull fracture & $1: 31370(10000$ to 100000 & $1: 6663(2200$ to 21000$)$ \\
With skull fracture & $1: 81+47$ to 140$)$ & $1: 29(12$ to 67$)$
\end{tabular}

TABI.F. III-Relative risk of intracranial haematoma in adults with head injury by cause of injury, consciousness, sex, and skull fracture

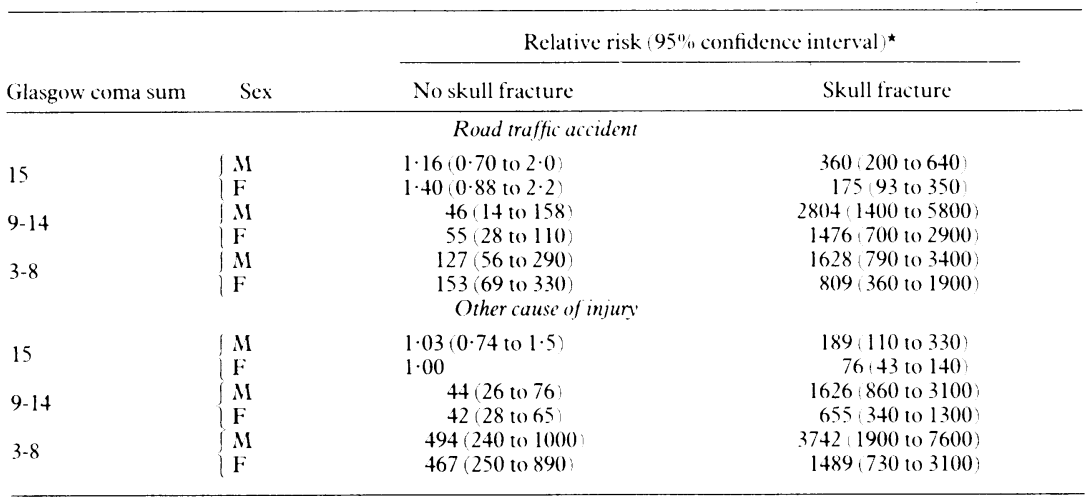

*Taking as reference a female patient not injured in a road traftic accident with a coma sum of 15 and no skull fracture.

TABLE IV - Estimated numbers of patients attending hospital with head injury/year/million total population and number with traumatic intracranial haematoma

\begin{tabular}{|c|c|c|}
\hline & No atlending hospital & $\begin{array}{c}\text { No with intracranial } \\
\text { haematoma }\end{array}$ \\
\hline & Adults & \\
\hline \multicolumn{3}{|l|}{ Without skull fracture: } \\
\hline \multicolumn{3}{|l|}{ Fully conscious } \\
\hline Without history of altered consciousness & 8800 & $0 \cdot 7$ \\
\hline With history of altered consciousness & 1900 & $0 \cdot 7$ \\
\hline With Impaired consciousness & 630 & $3 \cdot 5$ \\
\hline In coma & 75 & $2 \cdot 8$ \\
\hline \multicolumn{3}{|l|}{ With skull fracture: } \\
\hline Fully conscious & 150 & $3 \cdot 3$ \\
\hline With impaired consciousness & 49 & $9 \cdot 6$ \\
\hline In coma & 46 & $12 \cdot 7$ \\
\hline & Children & \\
\hline \multicolumn{3}{|l|}{ Without skull fracture: } \\
\hline Fully conscious & 8100 & $0 \cdot 6$ \\
\hline With impaired consciousness & 280 & 0.5 \\
\hline In coma & 26 & $0 \cdot 4$ \\
\hline \multicolumn{3}{|l|}{ With skull fracture: } \\
\hline Fully conscious & 110 & $0 \cdot 7$ \\
\hline With impaired consciousness & 19 & 0.8 \\
\hline In coma & 12 & $1 \cdot 0$ \\
\hline
\end{tabular}

\section{Discussion}

Our reports of the risks of intracranial haematoma in adults $^{3}$ and of the benefits of earlier detection and evacuation of haematomas ${ }^{1}$ have led to the development of guidelines for the initial management of adults with head injury in the United Kingdom. ${ }^{+}$This study, based on a larger number of patients, provides new data on the risks of a traumatic haematoma in adults and children. The patterns of effects of a skull fracture and of conscious level were similar in the two age groups even though different sources of data were used to calculate the risks. The overall concordance in the findings supports the validity of the analysis and allows policies to be developed for patients of all ages with head injury.

Half the patients with head injury attending accident and emergency departments are aged $\leqslant 14$ years, ${ }^{\circ}$ but data on the risk of a haematoma in children have been lacking until now. The overall lower risk found in this study in children partly reflected the greater number who attended hospital after a minor injury. Even when this was taken into account and patients were grouped by their level of consciousness and presence of a fracture, children were still significantly less at risk. The exclusion of children with fluid subdural collecttions means that we should be cautious in applying our findings to children suspected of non-accidental injury and to infants under 2 years old. In such children other clinical features, such as retinal haemorrhages or anaemia, may provide additional clues to an intracranial collection.

An alteration in conscious level is the characteristic consequence of traumatic brain damage, and our results confirmed its value as an index of the risk of a haematoma. Its influence was more pronounced in patients who did not have a fracture, among whom coma increased the risk of a clot almost 300 -fold in adults and 200 -fold in children, compared with a fully conscious patient. Even in adults who were fully conscious the history of a preceding episode of altered consciousness significantly increased the risk of a clot, although the effect was smaller than for other risk factors (table II). A record of careful assessments of consciousness before and on arrival at hospital remains an important component of managing head injury.

The value of radiography of the skull after head injury has been much debated. One reason for doubts about its usefulness for head injuries in children may have been evidence that extradural clots occur without a fracture more commonly in children than in adults. ${ }^{13}$ This may have given an erroneous impression that a fracture is uncommon whereas other reports have shown that a least three quarters of children with an extradural clot have skull fracture. ${ }^{1+16}$ In this study we included all types of acute haematoma; extradural, subdural, and intracerebral; more children than adults did not have a fracture $(38 \% v 23 \%$ respectively), but, overall, the effect of the presence of a fracture on the risk was only slightly less powerful in children.

Another reason for uncertainty about the value of skull radiography may be that few reports have considered separately the effects of a skull fracture and of conscious level. Two recent studies accord with our findings of the value of skull radiography in patients without marked impairment of consciousness. A "surgical lesion" was found in 11 of 105 adults with a "minor" head injury (who were alert and orientated or confused) who had a skull fracture but in none of 77 similar patients without a fracture. ${ }^{12}$ In a consecutive series of children with "moderate" head injury (with a history of impaired consciousness) three of 52 with a fracture had a surgically significant clot but none of 506 without a fracture. ${ }^{18}$ The evidence is clear that a skull fracture is a valuable index of the risk of an acute intracranial haematoma, both in children and in adults.

Without data on risks in children with head injury there have been various views about how such children should be managed. ${ }^{19} \mathrm{~A}$ more liberal approach has been usual, with more willingness to admit children to hospital. ${ }^{20}$ Some advocate a more selective approach, however, and return many children to their parents, who are given advice about observation and what to do in the event of neurological deterioration. ${ }^{1221}$ Although our data showed that children with head injury are at less risk than adults, the broad similarity of the patterns of their risks argues for similar policies and guidelines for both age groups.

The recommendations for adults recognised three different levels of risk. ${ }^{+}$The largest group of patients (without a skull fracture or impaired consciousness) was at lowest risk; advice that such patients can safely be observed at home has indeed reduced hospital admissions. ${ }^{223}$ The smallest group of patients (either with a fracture and impaired consciousness or in a persisting coma) were known to be at highest risk, and their earlier referral to neurosurgical units for computed tomography without waiting for deterioration has improved outcome. ${ }^{122}$ Patients in the intermediate group account for only $7 \%$ of those with head injury but nearly a third of significant intracranial haema- 
tomas. Our new analysis did not produce new subgroups with risks close to the existing high or low risk groups (table I). Although statistically significant, the new subgroups are of limited clinical use.

Several centres have reported improved outcomes owing to management policies that achieve early computed tomography of patients with intracranial lesions. ${ }^{23-26}$ The United Kingdom guidelines recommended that patients at intermediate risk should be observed in primary surgical wards and referred to neurosurgeons only if deterioration occurred. ${ }^{+}$This reflected the perception in the early 1980s that computed tomography in all of these patients was not feasible because of limited facilities. A recent audit in our unit, however, has shown that avoidable death and disability are common when such patients develop a clot. A recent study in 41 North American hospitals also showed that such low risk patients accounted for most of the excess mortality among units. ${ }^{27}$ The question now is how to alter policies and guidelines as computed tomographic scanners become more available in general hospitals so that more patients may benefit from early detection of an intracranial haematoma.

The simplest change would be to extend the indications for computed tomography to include patients who have a skull fracture who are fully conscious. This would require some 260 additional computed tomograms per year per million population but would still leave a fifth of patients at risk from delayed detection of a haematoma. The optimum approach would therefore be for all patients with persisting impaired consciousness or coma to have computed tomography. Radiography of the skull will become unnecessary for triage of such cases when computed tomography is available. This will bring British practice into line with that in most of North America ${ }^{28}$ and parts of Europe. ${ }^{17}$ Skull radiography will remain valuable for the many patients who are fully conscious who fulfil the criteria described for children" and adults. ${ }^{40}$ Conscious patients shown to have a fracture should then have computed tomography.

The new policy will require computed tomography of a further 1200 patients per million population per year, which is beyond the capacity of neurosurgical units but might be implemented by general hospitals that have facilities for computed tomography. Each would probably scan only four to five patients with head injury/week but would need arrangements for them to be investigated at short notice and often outside normal working hours. This would make major demands on staffing, and detailed arrangements will need to be worked out locally, taking account of the distribution of computed tomographic scanners in Britain. ${ }^{31}$ One approach might be for general hospitals to concentrate cover on the peak times for head injuries-early evenings and Friday and Saturday

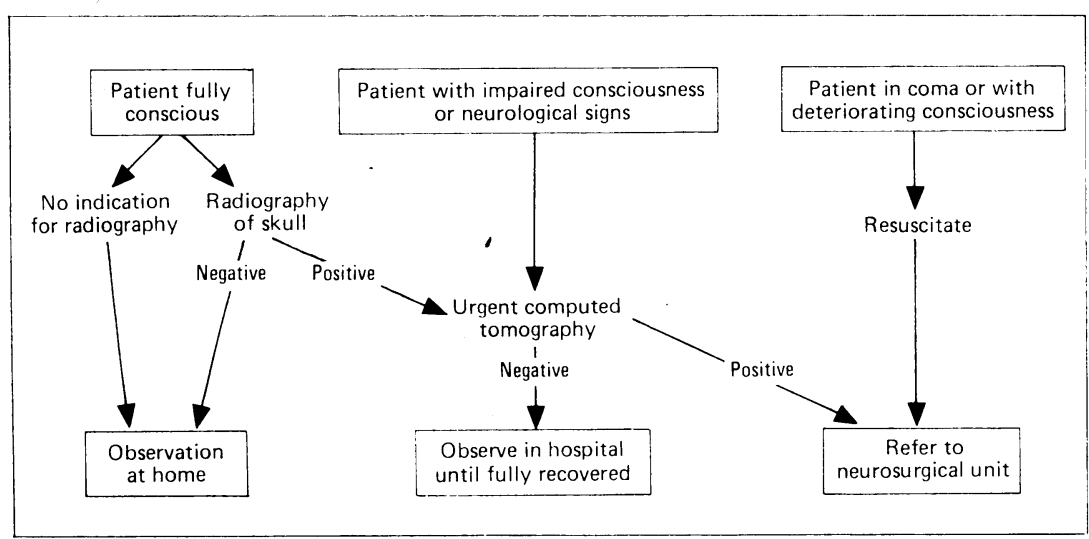

Management of patients with head injury in a general hospital with facilities for computed tomography
Indications for computed tomography in general hospitals

- Full consciousness but with a skull fracture

- Confusion persisting after initial assessment and resuscitation

- Unstable svstemic state precluding transfer to neurosurgery

- Diagnosis uncertain

Indications for referral to neurosurgical unit

Without preliminary computed tomography

- Coma persisting after resuscitation

- Deteriorating consciousness or progressive focal neurological deficits

- Open injury: depressed fracture of vault or basal skull fracture

- Patient fulfils criteria for computed tomography in a general hospital when this cannot be performed within a reasonable time - for example, three to four hours

After computed tomography in general hospital

- Abnormal tomogram (after neurosurgical opinion on images transferred electronically)

- Tomogram considered to be normal but patient's progress is unsatisfactory.

nights. Neurosurgical units might provide the service for intermediate risk cases during the remaining nights and would continue at all times to accept high risk patients whose transfer should not be delayed by preliminary computed tomography in a general hospital. Conversely, a patient with severe multiple injuries and a head injury might be scanned locally to avoid unnecessary transfer.

The new guidelines would require computed tomography for some $7 \%$ of patients with head injury but should achieve the early detection of $95 \%$ of intracranial haematomas. A remediable haematoma would be disclosed in some $3 \%$ of the patients investigated. In another 5-10\% computed tomography would show an abnormality requiring expert neurosurgical assessment, monitoring, and, in many cases, repeat scanning. Another benefit of the additional scanning will be that patients whose tomogram is normal may either not need to be admitted or might be discharged early. Many of these patients at present occupy a bed in a primary surgical ward for several days.

Wherever initial computed tomography is done neurosurgeons will continue to have a central role in managing head injuries. Emergency computed tomography needs expert interpretation; this might be achieved by consultation about electronically transferred images. But when a traumatic haematoma is shown its evacuation and further management are most appropriate in a neurosurgical unit. Three out of four patients with a haematoma have an intradural (subdural or intracerebral) clot, operation on which demands neurosurgical facilities and skill; even an extradural haematoma is usually evacuated more rapidly and effectively by transfer to a neurosurgical unit.

Whether computed tomography is performed in a general hospital or after transfer to a neurosurgical unit effective resuscitation must first be achieved; failure to correct or avoid hypoxia and hypotension is disastrous in a patient with serious head injury, irrespective of the findings on computed tomography. ${ }^{32}$ Improved arrangements for transfer of patients within and among hospitals are needed ${ }^{33}$; if computed tomography is carried out before the onset of neurological deterioration transportation may be arranged more deliberately and more safely.

We conclude that a skull fracture and an impaired conscious level are powerful indicators of the risk of an 
acute traumatic intracranial haematoma at all ages. Children with head injury can be managed by guidelines similar to those already used in adults, but to improve outcome even more patients should be investigated by computed tomography soon after injury. We therefore recommend that a patient with head injury who has either a persisting alteration in conscious level or a skull fracture should be investigated by computed tomography. The figure shows how this might be achieved through coordinated efforts by neurosurgical units and general hospitals with facilities for computed tomography. The box shows guidelines proposed as a basis for formulating new, locally agreed criteria for managing children and adults with head injuries.

This work was supported by the Medical Research Council and the chief scientist, Scottish Home and Health Department. We thank our colleagues for allowing us to use their original data.

1 Teasdale G, Galbraith S, Murray L, et al. Management of traumatic intracranial haematoma. Br Med $\mathcal{f}$ 1982;285: 1695-7.

2 Rockswold GL, Leonard PR, Naquib MG. Analysis of management in thirty threeclosed head injury patients who "talked and deteriorated." Neurosurgery 1987;21:51-5.

3 Mendelow AD, Teasdale G, Jennett B, et al. Risks of intracranial haematoma in head injured adults. Br Med 7 1983;287:1173-6.

4 Briggs $M$. Clarke P, Crockard A, et al. Guidelines for initital management after head injury in adults. Suggestions from a group of neurosurgeons. $B$ Med f 1984;288:983-5.

5 Brookes $M$, MacMillan R, Cully S, et al. Head injuries in accident/emergency departments. How different are children from adults? $\mathcal{F}$ Epidemiol Community Health (in press)

6 Strang I, MacMillan R, Jennett B. Head injuries in accident and emergency departments at Scottish hospitals. Injury 1987;10:154-9.

7 Swann I, MacMillan R, Strang I. Head injuries at an inner city acciden department. Injury 1982;12:274-8.

8 Jennett B, Macmillan R. Epidemiology of head injury. Br Med $\mathcal{J}$ 1981; 282:101-7.

9 Thillainayagam K, MacMillan R, Mendelow AD. How accurately are fractures of the skull diagnosed in an accident and emergency department? fractures of the skull digr
Injury 1987;18:319-21.

10 Teasdale G, Jennett B. Assessment and prognosis of coma after severe head injury. Acta Neurochir(Wien) 1976:34:45-55.
11 Morris JA, Gardner MJ. Calculating confidence intervals for relative risks odds ratios) and standardised ratios and rates. Br.Med f 1988;296:1313-6. Bishop YMM, Fienberg SE, Holland PW. Discrete multivariate analysis. Cambridge: Massachusetts Institute of Technology: Press, 1975.

13 Galbraith SL. Age distribution of extradural haemorrhage without skull fracture. Lancet 1973;ii:1217-8.

14 Mazza D, Pasqualin A, Feriott IG, Dapian R. Traumatic extradural haematomas in children: experience with 62 cases. Acta Neurochir (Wein) 1982;65:67-80.

15 Dhellemnes P, Legaine JP, Christiaens JL, et al. Traumatic extradural hematomas in infancy and childhood. I Neurosurg 1985;62:861-4.

6 Leggate JRS, Lopez-Ramos N, Genitori L, et al. Extradural haematoma in infants. British Yournal of Neurosurgery 1989;3:533-41.

17 Servadei F, Ciucci G, Morichetti A, et al. Skull fracture as a factor of increased risk in minor head injuries. An indication for a broader use of cerebral CT scanning. Surg Neurol 1988:30:364-9.

18 Rosenthal BW, Bergman I. Intracranial injury after moderate head trauma in children. I Pediatr 1989;115:346-50.

19 Dershewitz RA, Kaye BA, Swisher CN. Treatment of children with post traumatic loss of consciousness. Pediatrics 1983;72:602-7.
traut

20 Snoek JW, Minerhoud JM, Wilmink JT. Delayed deterioration following mild head injury in children. Brain 1984;107:15-36.

21 Sainsbury CPQ, Sibert JR. How long do we need to observe head injuries in hospital? Arch Dis Child 1984;59:856-9.

22 Fowkes FGR, Evans RC, Williams LA, et al. Implementation of guidelines for the use of skull radiographs in patients with head injuries. Lancet 1984; ii: $795-7$.

23 Miller JD, Tocher JL, Jones PA. Extradural haematoma-earlier detection, better results. Brain Injury 1988;2:83-6.

24 Bowers SA, Marshall LF. Outcome in 200 consecutive cases of severe head injury treated in San Diego County: a prospective analysis. Neurosurg. 1980;6:237-42

25 Cordobes F, Lobato RD, Rivas JJ, et al. Observations on 82 patients with extradural hematoma. Comparison of results before and after the advent of extradural hematoma. Comparison of results before

26 Bricolo AP, Parker LM. Extradural haematoma: toward zero mortality. Neurosurgery 1984;14:8-12.

27 Klauber MR, Marshall LF, Iverssen TG, et al. Determinants of head injury mortality: importance of the low risk patient. Neurosurgery 1989;24:31-6. 28 Thornbury JF, Masters SJ, Campbell JA. Imaging recommendations for head trauma: a new comprehensive strategy. $A \mathcal{F} R$ 1987;149:781-3.

29 Leonidas JC, Ting W, Binkiewicz A, et al. Mild head trauma in children: when is a roentgenogram necessary? Pediatrics 1982;69:139-43.

30 Royal College of Radiologists. Patient selection for skull radiography in uncomplicated head injury. Lancet 1983; ; 115-8.

31 Hewett RL, Wood VA. Availability of computed tomography of the brain in the United Kingdom. BrMed f 1989;298:1219-20.

32 Kohi YM, Mendelow AD, Teasdale GM, et al. Extracranial insults and outcome in patients with acute head injury-relationship to the Glasgow outcome scale. Injury 1984;16:25-9.

33 Gentleman D, Jennett B. Hazards of inter-hospital transfer of comatose head injured patients. Lancel 1981;ii:853-5.

(Accepted 1/ December 1989)

\section{Comparison of visual and radiographic detection of bony changes at the knee joint}

\section{Juliet Rogers, Iain Watt, Paul Dieppe}

Rheumatology Unit, Bristol Royal Infirmary, Bristol BS2 8HW

Juliet Rogers, $\mathrm{MB}$, lecturer in palaeopathology

Iain Watt, FRCR, consultant radiologist

Paul Dieppe, FRCP, professor

Correspondence to: Dr Rogers.

BrMed $\mathcal{F} 1990 ; 300: 367-8$
Osteoarthritis is often reported in human bones recovered from archaeological sites. The diagnosis is usually based on the presence of osteophytes with or without surface pitting, eburnation, or change of contour of the bony articular surface.' Clinicians diagnose osteoarthritis largely on the basis of changes visible on radiography, including narrowing at the joint space, osteophytes, subchondral eburnation, and cysts. ${ }^{2}$ The sensitivity of radiography in detecting pathological changes in bone has not been examined but is important in several disciplines. We investigated this by examining 24 knee joints visually and radiographically for changes compatible with osteoarthritis.

\section{Methods and results}

We selected 24 knee joints from 14 skeletons with a range of changes induced by osteoarthritis (normal to severe). The joints were assessed visually by a palaeopathologist (JR), who graded any osteophytes, eburnation, pitting, and alteration of bony contour as 1 (mild), 2 (moderate), or 3 (severe). Charts were drawn to show the extent and distribution of the changes, and the bones were photographed. The bones were then aligned in the anatomical position, and an anteroposterior radiograph was taken (the joint space, obviously artificial, was not included in the assessment). The $x$ ray films were examined by a radiologist (IW), who was unaware of the visual findings. Any osteophytes and other changes caused by osteoarthritis were graded as above. The visual and radiographic assessments were then compared (figure).

Eight of the 24 knee joints were normal by both techniques. Changes were noted on visual assessment in 16 but radiographically in only two. Osteophytes alone were detected visually in 11 knees (seven grade 1 , three grade 2 , and one grade 3 ), but only one of these knees was abnormal on radiography. Severe osteophytosis with other bony changes was seen in five knees, two of which had severe eburnation on the articular surface; one of these joints showed evidence of osteoarthritis on radiography.

\section{Comment}

We chose to study the knee joint because it is the commonest site for osteoarthritis and because we could obtain $x$ ray films of the disarticulated bones in the anatomical position fairly easily. We could not obtain satisfactory lateral $x$ ray films because of difficulties with alignment, so the study compared visual inspection of all aspects of the tibia and femur with a single anteroposterior radiograph. The comparison, however, was acceptable: palaeopathologists rely on looking at the whole area of the joint, whereas clinicians use an anteroposterior radiograph as their main aid to diagnosing osteoarthritis. The discrepancy between visual 